\title{
TRANSFORMAÇÕES QUÍMICAS DA MATÉRIA ORGÂNICA DURANTE A COMPOSTAGEM DE RESÍDUOS DA INDÚSTRIA MADEIREIRA
}

Cristiane R. Budziak, Claudia M. B. F. Maia e Antonio S. Mangrich*

Departamento de Química, Universidade Federal do Paraná, CP 19081, 81531-970 Curitiba - PR

Recebido em 2/4/03; aceito em 3/11/03

\begin{abstract}
CHEMICAL TRANSFORMATIONS OF ORGANIC MATTER DURING THE COMPOSTING OF WOOD INDUSTRY WASTES (RESIDUES). Composting of sawdust and paper mill sludge, using a "Kneer" process reactor, was studied in an attempt to elaborate upon organic matter $(\mathrm{OM})$ transformation during the process and to define parameters to measure the compost maturity level. Temperature, electron paramagnetic resonance (EPR) data, ash and $\mathrm{C}, \mathrm{H}, \mathrm{N}$ and $\mathrm{S}$ contents, and a spectroscopic method using ultraviolet-visible (UV-VIS) for alkaline $(\mathrm{pH}=8.5$ ) and solid samples was used to study the maturity of the compost samples. These parameters were measured in 6 humic acids (HA) extracted from the compost samples during 29 days. The results of this work show that the "Kneer" process is efficient in transforming ligno-celulitic residues in a short time (29 days), into an organic fertilizer material with application perspectives.
\end{abstract}

Keywords: humic acid structures; composting of sawdust; paper mill sludge.

\section{INTRODUÇÃO}

\section{A matéria orgânica de solos, águas e sedimentos orgânicos}

O húmus, ou matéria orgânica do solo (MOS), devido ao seu papel vital na manutenção da qualidade do solo, é fator chave nas modernas práticas de manejo sustentado da terra. A conservação e o aumento do húmus no solo exercem efeitos benéficos no suprimento dos nutrientes para as plantas, na estrutura e na compactabilidade do solo, e na capacidade de retenção de água ${ }^{1}$.

A MOS designa um conjunto de substâncias altamente heterogêneo que inclui numerosos compostos de carbono, variando de açúcares, proteínas e outros constituintes biológicos, ácidos orgânicos de baixas massas moleculares, como os ácidos acético e oxálico, quase todos facilmente mineralizáveis, até o conjunto complexo de produtos recalcitrantes resultantes de transformações químicas e microbianas da MOS, as substâncias húmicas $(\mathrm{SH})$. Os principais constituintes das $\mathrm{SH}$, tanto quantitativa quanto qualitativamente, são os ácidos húmicos $(\mathrm{AH})^{2}$.

Recentemente, uma discussão emergiu na comunidade científica sobre o tipo real de estrutura molecular dos AH: se são constituídos de estruturas macromoleculares como sempre se afirmou, ou se de estruturas supramoleculares, resultantes da associação de blocos moleculares relativamente pequenos, através de ligações de hidrogênio, associações de orbitais $\pi-\pi$, ou usando íons metálicos como $\mathrm{Fe}(\mathrm{III}), \mathrm{Al}(\mathrm{III})$ ou $\mathrm{Cu}(\mathrm{II})$ como mordentes ${ }^{3}$.

Em ciências húmicas, a composição refere-se à funcionalidade e às moléculas componentes. Normalmente, os cientistas de SH definem as estruturas químicas dos $\mathrm{AH}$ como macromoléculas complexas, constituídas de diferentes estruturas aromáticas e alifáticas com funções carboxílicas e fenólicas. Estas estruturas estão ligadas a peptídeos e outros compostos contendo nitrogênio e carboidratos em pequenas quantidades ${ }^{4}$. Dados de espectroscopias de ressonância paramagnética eletrônica, fotoacústica, infravermelho e cálculos de combinação linear de orbitais atômicos - orbitais moleculares - e de campo ligante (CLOA-OM-CL) foram utilizados para estudar a

*e-mail: mangrich@quimica.ufpr.br conexão de blocos de AH através da complexação com metais. Determinou-se o caráter da ligação e o tipo de sítio da matéria orgânica que se ligava a íons vanadilo, de $\mathrm{AH}$ naturais ${ }^{5}$ e sintéticos $^{6}$, para formar grandes blocos moleculares. Nestes casos, constatou-se que as estruturas supramoleculares se formavam através da união de grupos salicilatos das estruturas dos blocos moleculares menores e os íons VO(II) como pontes. Mais recentemente, utilizaram-se as sondas paramagnéticas $\mathrm{VO}(\mathrm{II})$, como modelo de ácido duro, e $\mathrm{Cu}$ (II), como modelo de ácido mole, para estudo de sítios de complexação de íons metálicos em estruturas de melaninas sintéticas ${ }^{7}$. Melaninas sintetizadas por fungos e actinomicetos no solo são precursoras de $\mathrm{AH}^{8-10}$.

\section{Os resíduos da indústria madeireira no Brasil}

Segundo a "Food and Agriculture Organization" (FAO), das Nações Unidas, a indústria madeireira movimentou no mundo, US\$ 450 bilhões em 1999. Por isso, o BNDES ressalta a necessidade de se investir em reflorestamento no Brasil. Em 2001, o PIB florestal brasileiro atingiu R $\$ 21$ bilhões, com exportações de US\$ 4 bilhões. Para a Sociedade Brasileira de Silvicultura $(\mathrm{SBS})^{11}$, o potencial do nosso país, que possui a segunda maior cobertura florestal do mundo, é ultrapassar US\$ 11 bilhões com vendas externas, em 2010. A produção de madeira de reflorestamento no Brasil, principalmente com Pinus taeda e Eucalyptus grandis, vem crescendo de forma acentuada. Somente o Estado do Paraná produziu, em 2000, 22,8 milhões de $\mathrm{m}^{3}$ de madeira retirada de suas florestas plantadas ${ }^{11}$. Considerando-se que a eficiência de aproveitamento tenha sido de $50 \%$, a industrialização deste volume gerou cerca de 11,4 milhões de $\mathrm{m}^{3}$ de rejeitos $^{12-13}$.

Normalmente parte dos rejeitos é queimada a céu aberto e parte, principalmente serragem, é removida para aterros inadequados, acarretando o desprendimento de chorume, de alta carga orgânica tóxica, provocando danos ao ambiente, principalmente em córregos, rios e mananciais de uso municipal ${ }^{12,13}$.

A alternativa de aproveitamento da serragem como fertilizante orgânico, em aplicação direta no solo, leva à imobilização de nutrientes essenciais e altas concentrações de espécies químicas reduzi- 
das, sendo típicas as presenças de $\mathrm{Mn}^{2+}$ e $\mathrm{Fe}^{2+}$, em vez de $\mathrm{MnO}_{2}$ e $\mathrm{Fe}^{3+}$, respectivamente. $\mathrm{O}$ baixo teor de $\mathrm{N}$ nas estruturas químicas da serragem é um fator desfavorável para sua degradação microbiológica $^{14}$, levando à necessidade da adição de outros materiais, mais ricos em N, com vistas ao aumento da relação N/C. O lodo dos despejos de fábricas de papel e celulose, também ricos em estruturas de lignina, contém maiores concentrações de compostos de nitrogênio e fósforo, para facilitar sua biodegradação. Este lodo pode ser utilizado em mistura com a serragem, para formar material com maior relação N/C que a serragem pura.

\section{A lignina}

É um polímero derivado de grupos fenilpropanóides denominados $\mathrm{C}_{6} \mathrm{C}_{3}$ ou, simplesmente unidades $\mathrm{C}_{9}$, repetidas de forma irregular, que têm sua origem na polimerização desidrogenativa do álcool coniferílico. As ligninas são formadas a partir de três precursores básicos, que são os álcoois $p$-cumarílico, coniferílico e sinapílico (Figura 1). Algumas ligninas consistem de polímeros fenilpropanóides, da parede celular, altamente condensados e muito resistentes à degradação. Eles são compostos de unidades $p$-hidroxifenila $(\mathrm{H})$, guaiacila (G) e siringila (S) (Figura 2), em proporções diferentes, de acordo com sua origem.

As madeiras duras, ou angiospermas, contêm ligninas formadas principalmente de unidades $\mathrm{G}$ e $\mathrm{S}$. As madeiras moles, ou gimnospermas, possuem ligninas formadas fundamentalmente de unidades G. Ligninas de gramíneas compreendem unidades G-S-H. Existem, no entanto, ligninas de certas espécies de gimnospermas e de gramíneas que apresentam abundância de unidades G e S. O grupo metoxílico é considerado um grupo funcional característico de ligninas e seus derivados ${ }^{15}$.<smiles>OCC=Cc1ccc(O)cc1</smiles><smiles>COc1cc(C=CCO)ccc1O</smiles><smiles>COc1cc(C=CCO)cc(OC)c1O</smiles>

Álcool sinapílico Álcool coniferílico Álcool $p$-cumarílico

Figura 1. Precursores básicos na formação da molécula de lignina<smiles>Cc1ccc(O)cc1</smiles>

$p$ - hidroxifenila<smiles>COc1cc(C)ccc1O</smiles>

guaiacila<smiles>COc1cc(C)cc(OC)c1O</smiles>

siringila
Figura 2. Principais unidades aromáticas presentes na molécula de lignina

\section{A compostagem}

É um processo biológico aeróbio de tratamento e estabilização de resíduos orgânicos para a produção do composto, nome dado ao fertilizante orgânico assim produzido ${ }^{12}$. Durante a compostagem, a matéria orgânica é decomposta principalmente através da ação de microorganismos e enzimas, resultando na fragmentação gradual e oxidação dos detritos ${ }^{12}$.

Há quatro caminhos distintos propostos para a síntese de substâncias húmicas no ambiente ${ }^{4}$, os quais podem também ocorrer na formação de SH durante a compostagem: a) amino compostos de síntese microbiana reagem com ligninas modificadas; b) polifenóis oxidados a quinonas reagem com amino compostos; c) reação de açúcares redutores com amino compostos e d) polimerização de melaninas produzidas por fungos e por actinomicetos do solo. No último mecanismo, estruturas orgânicas simples são transformadas em material condensado de cor escura, com teores de nitrogênio relativamente altos. A aromatização das estruturas das SH é conseqüência de atividade microbiana ${ }^{8-10} \mathrm{e}$, também, das estruturas químicas do material de partida.

Filley et $a l .{ }^{16}$ estudando a atividade de fungos basidiomicetos em madeira apodrecida (podridão parda) de florestas de coníferas (Pinus taeda) verificaram que durante a degradação de lignina e celulose, simultaneamente, os grupos metoxílicos de ligninas são removidos, gerando grupos aromáticos ricos em hidroxilas, produzidos abundantemente na forma orto-di-hidroxi (catecol). O mecanismo de "podridão parda" envolve a ação da química de Fenton $\left(\mathrm{Fe}^{+2}+\mathrm{H}_{2} \mathrm{O}_{2}\right)$ para a produção de ânions e radicais hidroxilas. Os compostos fenólicos produzidos pela ação do fungo são queladores de ácidos duros, como íons $\mathrm{Fe}^{3+}$, e fonte de elétrons na redução destes íons férricos.

Neste trabalho estudou-se a compostagem de serragem em reator do tipo "Kneer", o qual utiliza a oxigenação forçada do material, melhorando-se a relação N/C pela adição de lodo de fábrica de celulose ${ }^{13}$.

A compreensão da química do processo de compostagem pode contribuir para definir parâmetros químicos que expressem a qualidade agro-ambiental do composto obtido. Para isto, acompanhou-se as alterações químicas e espectroscópicas de AH extraídos de amostras de composto, para se determinar o grau de maturidade de compostos de serragem de Pinus taeda em mistura com lodo de fábrica de celulose, em diferentes dias de compostagem.

\section{PARTE EXPERIMENTAL}

A compostagem da serragem de Pinus taeda e lodo de fábrica de papel e celulose foi acompanhada em reator com capacidade para 13 toneladas de material de partida, pelo processo "Kneer". O material para a compostagem foi preparado por homogeneização dos substratos, em proporção de $50 \%$ em volume de cada constituinte. $\mathrm{O}$ equipamento utilizado faz parte da Usina Piloto da Empresa Tibagi Empreendimentos Ambientais, que está instalada na periferia do município de São José dos Pinhais - PR. O reator funciona com controle automático de um microcomputador, sob fluxo forçado de ar e leitura constante da temperatura. Amostras do material foram tomadas nos seguintes tempos de compostagem: 0 (A0), 2 (A1), 8 (A2), 15 (A3), 22 (A4) e 29 dias (A5). As amostras foram transportadas para o laboratório em sacos de plástico incolor, apropriados para amostragem de solos e sedimentos, secas a $60^{\circ} \mathrm{C}$, moídas e peneiradas (peneira de $2 \mathrm{~mm}$ ) e armazenadas em refrigerador $\left(\sim 5^{\circ} \mathrm{C}\right)$. Os ácidos húmicos $(\mathrm{AH})$ foram extraídos de cada amostra por solubilização em álcali e precipitação em ácido ${ }^{17}$. Após a extração, as amostras de $\mathrm{AH}$ foram secas a $60{ }^{\circ} \mathrm{C}$, maceradas, e armazenadas em refrigerador. Os espectros de amostras líquidas, na região do UVVIS, foram obtidos em espectrofotômetro Shimadzu UV-2401 PC, a partir de solução de $3 \mathrm{mg}$ de $\mathrm{AH}$ solubilizados em $10 \mathrm{~mL}$ de solução de $\mathrm{NaHCO}_{3} 0,05 \mathrm{~mol} \mathrm{~L}^{-1}(\mathrm{pH}=8,5)$. Para a obtenção dos espectros das amostras de $\mathrm{AH}$ no estado sólido equipou-se o espectrofotômetro Shimadzu UV-2401PC com o acessório esfera de integração. Os es- 
pectros de RPE foram registrados na faixa de campo magnético de $50 \mathrm{G}$, em espectrômetro Bruker ESP 300E operando em banda -X (9,5 GHz), empregando $100 \mathrm{kHz}$ de freqüência de modulação e $2 \mathrm{G}$ de amplitude de modulação. Os teores de radicais livres orgânicos (spins $\mathrm{g}^{-1} \mathrm{AH}$ ) foram determinados usando-se a aproximação, intensidade da linha de EPR X $\Delta \mathrm{H}_{\mathrm{pp}}{ }^{2}$, onde $\Delta \mathrm{H}_{\mathrm{pp}}$ é a largura da linha. As áreas das linhas de EPR foram calibradas com áreas correspondentes do sinal de EPR de uma amostra referência ("weak pitch") de fator $\mathrm{g}(2,0028)$ e teor conhecido de radicais livres, obtida da Bruker.

Para a análise elementar $(\mathrm{C}, \mathrm{H}, \mathrm{N}$ e S) utilizou-se equipamento Fisons mod. EA $1108 \mathrm{CHNS}$, e as cinzas e umidade foram determinadas através da análise termogravimétrica em equipamento Netzach modelo STA 409, utilizando-se velocidade de aquecimento de $8{ }^{\circ} \mathrm{C} \mathrm{min}{ }^{-1}$, sob atmosfera dinâmica de $\mathrm{O}_{2}$ e $\mathrm{N}_{2}$, com vazão de gás de $100 \mathrm{~mL} \mathrm{~min}^{-1}$.

\section{RESULTADOS E DISCUSSÃO}

A Tabela 1 apresenta as variações do número de spins por grama de $\mathrm{AH}$, fator g e temperatura de compostagem para as amostras de ácido húmico, ao longo dos 29 dias da compostagem, de AHA0 a AHA5. Do início, amostra A0, até a amostra A1, aos 2 dias, o processo passou da fase mesofílica, onde atuam fungos, bactérias e actinomicetos, para a fase termofílica, onde atuam mais vigorosamente actinomicetos e bactérias. Neste período de 2 dias a temperatura passou de 26 para $65^{\circ} \mathrm{C}$. Da amostra A1, aos 2 dias, para a amostra $\mathrm{A} 2$, aos 8 dias, a temperatura subiu mais lentamente, até o máximo de $70^{\circ} \mathrm{C}$. Aos 15 dias de compostagem, amostra A3, o composto passou do reator para o pátio da fábrica, onde passou a ser revolvido, periodicamente, com auxílio de trator.

Tabela 1. Número de spins por grama de AH, fator g e temperatura, ao longo dos 29 dias de compostagem

\begin{tabular}{lccc}
\hline Amostras & Spin $\mathrm{g}^{-1} \mathrm{AH}$ & Fator $\mathrm{g}$ & Temperat. ${ }^{\circ} \mathrm{C}$ \\
\hline AHA0 & $3,73 \times 10^{15}$ & 2,0033 & 26 \\
AHA1 & $2,63 \times 10^{15}$ & 2,0033 & 65 \\
AHA2 & $7,62 \times 10^{15}$ & 2,0034 & 71 \\
AHA3 & $7,92 \times 10^{15}$ & 2,0033 & 58 \\
AHA4 & $7,54 \times 10^{15}$ & 2,0033 & 40 \\
AHA5 & $8,96 \times 10^{15}$ & 2,0033 & 33 \\
\hline
\end{tabular}

Neste período a temperatura diminuiu constantemente até próximo da temperatura ambiente, e foram coletadas as amostras A4, aos 22 dias de compostagem, e A5 aos 29 dias.

A Figura 3 apresenta a correlação entre temperatura do material em compostagem e o número de spins por grama dos $\mathrm{AH}$ extraídos. Observa-se que, no início, na fase termofílica, os dois parâmetros apresentam alguma correlação, até a amostra A3. A seguir, a temperatura do sistema cai e o teor de radicais livres orgânicos oscila, atingindo o valor máximo na amostra A5.

Os fatores g de EPR, com valores de 2,0033 a 2,0034, correspondem a estruturas de orto- e/ou para-semiquinonas formadas durante o processo de compostagem. Estas semiquinonas estão como intermediárias nas reações de redox de orto- e/ou para-difenolatos a orto- e/ou para-quinonas (Figura 4). Considerando-se as estruturas de guaiacila e siringila, componentes da lignina de madeira mole ou gimnosperma, ambas contendo estruturas orto-hidroximetoxila, conclui-se que os radicais livres orgânicos determinados, com $\mathrm{g} \approx 2,0033$, correspondem a orto-semiquinonas, formadas na cisão homolítica: $\phi-\mathrm{O}-\mathrm{CH}_{3} \rightarrow \phi-\mathrm{O}^{\circ}+{ }^{\circ} \mathrm{CH}_{3}$.

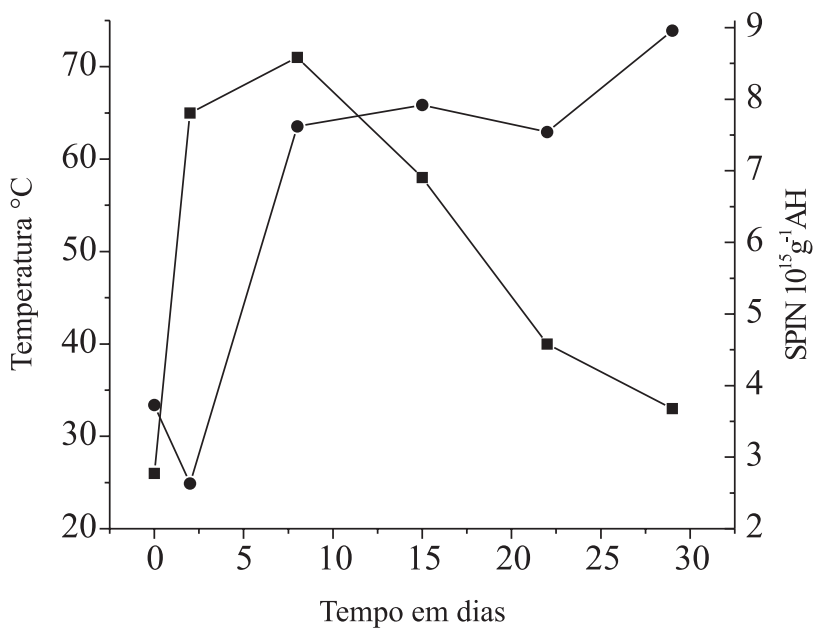

Figura 3. Correlação entre a temperatura do material compostado quando da coleta da amostra (ם) e o número de spins por grama de AH (-<smiles>COc1ccc([CH]C(C)C)c(OC)c1</smiles>

Figura 4. Semiquinonas produzidas pela redução de quinonas ou pela oxidação de para- $e$ orto- difenóis

A Tabela 2 apresenta os resultados de umidade e matéria orgânica das amostras de ácidos húmicos, assim como do lodo biológico e da serragem pura. Verifica-se que, em geral, o teor de $\mathrm{MO}$ diminui

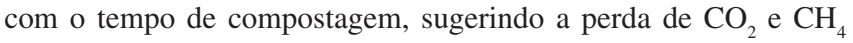
durante o processo.

Tabela 2. Percentagens de umidade e matéria orgânica (MO), em base seca, das amostras de AH, lodo e serragem. Dados obtidos por termogravimetria

\begin{tabular}{lrc}
\hline Amostras & Umidade $\%$ & MO \% \\
\hline AHA0 & 9,06 & 96,71 \\
AHA1 & 10,28 & 91,91 \\
AHA2 & 7,22 & 94,73 \\
AHA3 & 9,65 & 88,09 \\
AHA4 & 9,12 & 88,12 \\
AHA5 & 6,10 & 84,84 \\
Lodo & 11,00 & 91,32 \\
Serragem & 9,15 & 94,94 \\
\hline
\end{tabular}

A Tabela 3 mostra os dados de análise elementar para os AH, de $\mathrm{AHA} 0$ até $\mathrm{AHA} 5$, mais os dados médios de $\mathrm{AH}$ de vários solos de diferentes latitudes ${ }^{18}$, do lodo e da serragem. Segundo Rashid ${ }^{19}$, a composição elementar das substâncias húmicas (SH) pode variar consideravelmente, dependendo da fonte da matéria orgânica (MO), do grau de humificação, da massa molar e das condições ambientais. 
Tabela 3. Resultados de análise elementar de C, H, N, S e O e suas respectivas razões atômicas

\begin{tabular}{lcccccccc}
\hline Amostras & $\% \mathrm{C}$ & $\% \mathrm{H}$ & $\% \mathrm{~N}$ & $\% \mathrm{~S}$ & $\% \mathrm{O} *$ & $\mathrm{~N} / \mathrm{C}$ & $\mathrm{H} / \mathrm{C}$ & $\mathrm{O} / \mathrm{C}$ \\
\hline AHA0 & 52,72 & 6,04 & 4,14 & 7,84 & 29,26 & 0,07 & 1,37 \\
AHA1 & 50,55 & 5,86 & 4,50 & 6,38 & 32,71 & 0,07 & 1,39 \\
AHA2 & 48,98 & 5,48 & 3,92 & 6,66 & 34,96 & 0,07 & 1,34 \\
AHA3 & 51,31 & 5,77 & 4,32 & 5,94 & 32,66 & 0,07 & 1,35 \\
AHA4 & 50,70 & 5,91 & 4,35 & 5,66 & 33,38 & 0,07 & 1,40 \\
AHA5 & 52,88 & 6,36 & 4,76 & 5,87 & 30,13 & 0,08 & 1,44 \\
AH solo & 56,2 & 4,7 & 3,2 & 0,8 & 35,5 & 0,05 & 0,48 \\
Lodo & 47,57 & 5,59 & 4,15 & 7,33 & 35,36 & 0,07 & 0,49 \\
Serragem & 52,71 & 5,67 & 1,55 & - & 40,07 & 0,025 & 1,41 & 0,43 \\
\hline
\end{tabular}

$\% \mathrm{O} *$ determinada por diferença.

Ao contrário do que ocorre em síntese, ou análises químicas comuns, onde a análise elementar é utilizada para se estabelecer a composição molecular, na química de SH a análise elementar é importante para se ter idéia do tipo de estrutura e funções orgânicas das moléculas que compõem as SH de diferentes ambientes, ou com diferentes graus de maturação.

Neste trabalho, as percentagens de $\mathrm{C}$ e $\mathrm{H}$ diminuíram e depois aumentaram durante a compostagem. As percentagens de $\mathrm{C}$ eram sempre menores, e as de $\mathrm{H}$ sempre maiores que as médias encontradas para $\mathrm{AH}$ de solos. As percentagens relativas de $\mathrm{N}$ oscilaram, em média, acima de $4 \%$, e eram sempre maiores que aquelas encontradas para $\mathrm{AH}$ de solos. As percentagens de $\mathrm{S}$ diminuíram e as percentagens de $\mathrm{O}$ aumentaram e depois diminuíram, com o desenvolvimento da compostagem, e eram sempre menores que as encontradas para a média dos $\mathrm{AH}$ de solos. Os valores das razões atômicas N/C, outro dado típico de química de $\mathrm{SH}$, mantiveram-se constantes durante o processo de compostagem, e maiores que as médias para $\mathrm{AH}$ de solos. Elas têm sido usadas para identificar a fonte da matéria orgânica. Razões N/C mais elevadas indicam estruturas orgânicas mais alifáticas e proteináceas ${ }^{20}$. Razões H/C altas, como no caso deste trabalho, indicam, também, estruturas mais alifáticas. As razões $\mathrm{O} / \mathrm{C}$ aumentaram e diminuíram de valor no decorrer da compostagem, indicando processos oxidativos mais fortes no início da compostagem. A amostra AH05 possui a mais alta razão H/C e a segunda mais baixa razão $\mathrm{O} / \mathrm{C}$, sugerindo estruturas orgânicas mais reduzidas do que as amostras iniciais.

Os espectros de UV-VIS dos AH estudados, em solução e no estado sólido estão mostrados na Figura 5 e 6, respectivamente. Apresentam diminuições constantes nas suas intensidades, típicas de $\mathrm{SH}$. As razões $E_{2} / E_{4}^{\prime}\left(E_{2}\right.$ - absorbâncias em 270 nm e $E_{4}^{\prime}-$ em 407 nm) e $\mathrm{E}_{4} / \mathrm{E}_{6}\left(\mathrm{E}_{4}\right.$ - absorbâncias em 465 e $\mathrm{E}_{6}$ - em $\left.665 \mathrm{~nm}\right)$ são apresentadas nas Figuras 7 e 8 . As baixas razões $\mathrm{E}_{4} / \mathrm{E}_{6}$ estão diretamente relacionadas com o aumento da conjugação de ligações químicas simples e duplas, que nos AH de solos, ou sedimentos mais antigos, correspondem à condensação de grupos aromáticos. Nos AH novos aqui estudados, no entanto, podem representar também ligações químicas conjugadas em estruturas de grupos alifáticos insaturados. Estudos mostraram que este dado independe da concentração de material húmico, mas varia para materiais obtidos de diferentes tipos de solos e sedimentos ${ }^{20}$. A diminuição da razão $\mathrm{E}_{4} / \mathrm{E}_{6} \operatorname{com} \mathrm{o}$ tempo de compostagem sugere também interações de blocos moleculares menores via quelação de íons metálicos ácidos duros, como $\mathrm{Fe}^{3+}$ por exemplo, por grupos catecolatos oriundos da desmetilação de grupos metoxilas de estruturas do tipo siringila e/ou guaiacila.

No estado sólido, a razão $\mathrm{E}_{4} / \mathrm{E}_{6}$ é menor ainda porque, além do crescimento do número de ligações conjugadas, há a interação intermolecular própria de estado sólido (Figura 7). A razão $\mathrm{E}_{2} / \mathrm{E}_{4}{ }^{\prime}$ tem sido usada como método para distinguir as diferentes origens da

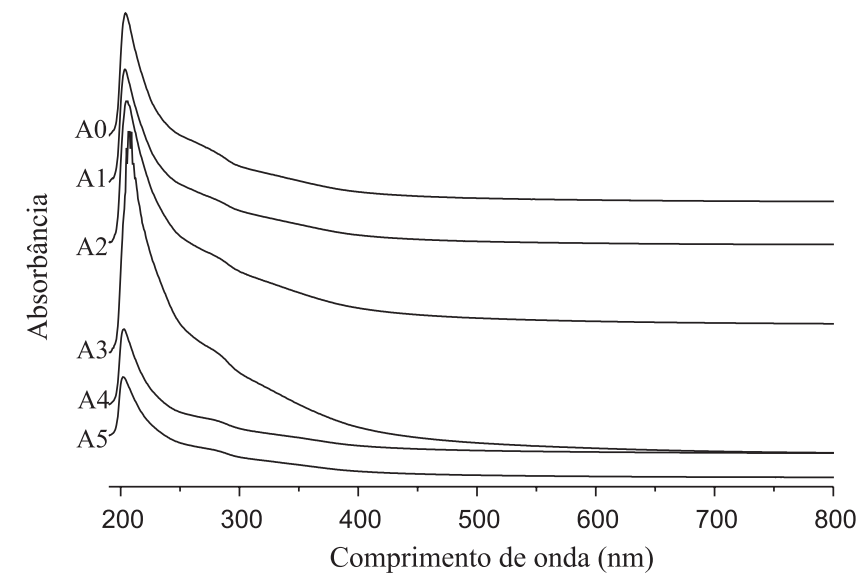

Figura 5. Espectros por ultravioleta-visível (UV-vis), amostras em solução, e por refletância (b), de O (A0), 2 (A1), 8 (A2), 15 (A3), 22 (A4), 29 dias (A5), lodo e serragem

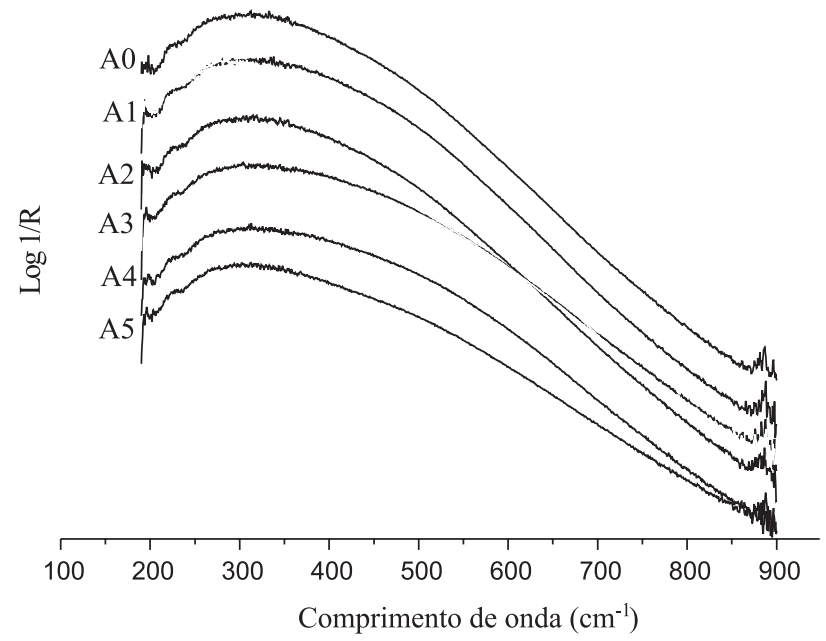

Figura 6. Espectros por ultravioleta-visivel ( $U V$-vis) por refletância, de 0 (A0), 2 (A1), 8 (A2), 15 (A3), 22 (A4), 29 dias (A5), lodo e serragem

matéria orgânica (MO) (Figura 8). A baixa razão $\mathrm{E}_{2} / \mathrm{E}_{4}$ ' está relacionada com a maior participação de estruturas porfirínicas (absorção em $407 \mathrm{~nm}$ atribuída à banda Soret de porfirinas) com relação a estruturas de ligninas. As porfirinas metaladas nestas amostras são originárias do lodo biológico usado na compostagem, ou da síntese biológica, durante o processo de compostagem, por microorganismos 
do tipo actinomicetos. A razão $\mathrm{E}_{2} / \mathrm{E}_{4}$ ' mais alta sugere a maior participação de plantas terrestres com altos níveis de estruturas de ligninas (absorção em $270 \mathrm{~nm})^{21}$. Nas amostras deste trabalho, observou-se queda constante da razão $\mathrm{E}_{2} / \mathrm{E}_{4}$ ' durante o período de oxigenação, dentro do reator. Tal queda corresponde à diminuição do teor de ligninas e/ou formação de estruturas de porfirinas. Após este período, com o material no pátio de compostagem, o comportamento da razão $\mathrm{E}_{2} / \mathrm{E}_{4}$ ' inverteu-se, indicando o consumo de estruturas porfirínicas nesta fase do processo, e/ou a formação de estrutura aromática não condensada ligada a funções oxigenadas (Figura 8).

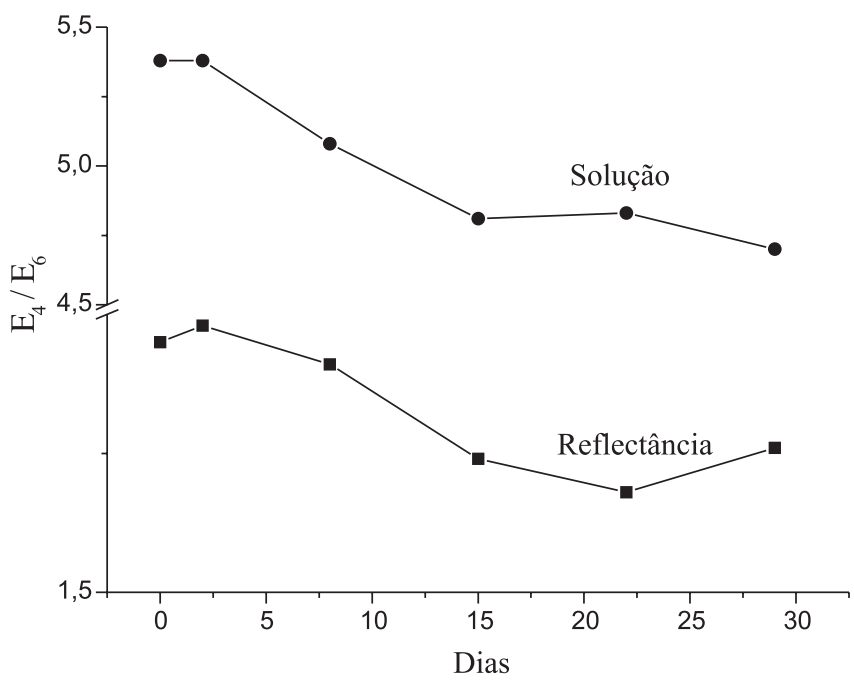

Figura 7. Razões $E_{4} / E_{6}$ em solução e em reflectância das amostras de ácidos húmicos durante a compostagem

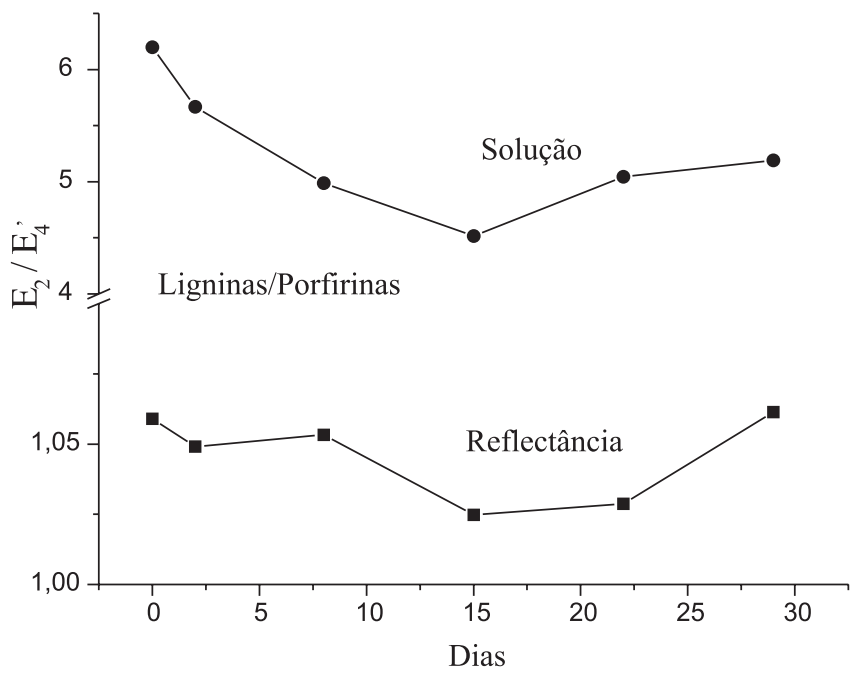

Figura 8. Razões $E_{2} / E_{4}{ }_{4}$ em solução e em reflectância das amostras de ácidos húmicos durante a compostagem

\section{CONCLUSÕES}

Os resultados deste trabalho mostram que o processo "Kneer", usado para a preparação do composto, é eficiente para a transformação de resíduos ligno-celulósicos, em curto espaço de tempo (29 dias), em material fertilizante orgânico com perspectivas de aplicação agroflorestal.

Os dados de spins por grama de $\mathrm{AH}$ estão, em geral, de forma inversa aos dados das razões $\mathrm{E}_{2} / \mathrm{E}_{4}$ ' e $\mathrm{E}_{4} / \mathrm{E}_{6}$ obtidos das análises por
UV-VIS, e indicam que houve quebra de ligação $\phi \mathrm{O}-\mathrm{CH}_{3}$ por cisão homolítica com formação de 2 radicais livres orgânicos, $\phi \mathrm{O}^{*} \mathrm{e}^{\circ} \mathrm{CH}_{3}$. As possíveis estruturas de orto-semiquinonas formadas reagem entre si produzindo aumento da cadeia orgânica aromática, ou com ${ }^{\circ} \mathrm{H}$ para formar grupo fenólico. Os radicais livres, ${ }^{\circ} \mathrm{CH}_{3}$, devem formar metano, gás liberado em pequenas quantidades no processo de compostagem, por reação com o ${ }^{*} \mathrm{H}$.

A análise elementar revelou razões $\mathrm{H} / \mathrm{C}$ e N/C mais elevadas que na média dos $\mathrm{AH}$ de solos, indicando que durante a compostagem a MO tornou-se mais alifática e rica em funções nitrogenadas. As razões $\mathrm{O} / \mathrm{C}$ aumentam e diminuem de valor no decorrer do processo de compostagem, indicando processos oxidativos no início, e de redução no final.

A diminuição da razão $\mathrm{E}_{4} / \mathrm{E}_{6}$, com o tempo de compostagem, indicou o aumento do número de cadeias orgânicas, com ligações simples e duplas conjugadas, durante o processo, o que pode corresponder a aumento, também, das estruturas supramoleculares.

Os resultados aqui obtidos, sugerem que os grupos ortosemiquinonas formados podem, por redução, formar estruturas ortodifenólicas, excelentes queladores de ácidos duros de Pearson, como os íons $\mathrm{Fe}^{3+}$. Na continuação deste trabalho será mostrado, por dados de espectroscopia de EPR, que íons $\mathrm{Fe}^{3+}$ inicialmente presentes na fase inorgânica do material sendo compostado passam para a fase orgânica, com o desenvolvimento do processo.

\section{AGRADECIMENTOS}

Ao CNPq, CAPES, Fundação Araucária do Paraná e ao Programa Paraná 12 Meses (Secretaria de Agricultura do PR e Banco Mundial) pelo apoio financeiro e bolsas PG e PQ. À Tibagi Empreendimentos Ambientais pelo uso do reator de compostagem, e ao LACTEC pelas análises de termogravimetria.

\section{REFERÊNCIAS}

1. Piccolo, A.; Nardi, S.; Concheri, G.; Soil Biol. Biochem. 1992, 24, 373.

2. Novotny, E. H.; Blum, W. E. H.; Gerzabek, M. H.; Mangrich, A. S.; Geoderma 1999, 92, 87.

3. Piccolo, A.; Nardi, S.; Concheri, G.; Eur. J. Soil Sci. 1996, 47, 319.

4. Hayes, M. H. B.; Clapp, C. E.; Soil Sci. 2001, 723.

5. Mangrich, A. S.; Vugman, N. V.; Sci. Total Environ. 1988, 75, 235.

6. Mangrich, A. S.; Vugman, N. V.; Fuel 1990, 69, 925.

7. Stainsack, J.; Mangrich, A. S.; Maia, C. M. B. F.; Machado, V. G.; Dos Santos, J. C. P.; Nakagaki, S.; Inorg. Chim. Acta 2003, 356, 243.

8. Pain, S.; Linhares, L. F.; Mangrich, A. S.; Martin, J. P.; Biol. Fert. Soil 1990, 10, 72 .

9. Gomes, R. C.; Mangrich, A. S.; Coelho, R. R. R.; Linhares, L. F.; Biol. Fert. Soil 1996, 21, 84.

10. Mangrich, A. S.; Lermen, A. W.; Santos, E. J.; Gomes, R. C.; Coelho, R. R. R.; Linhares, L. F.; Senesi, N.; Biol. Fert. Soil 1998, 26, 341.

11. http://www.ipef.br/serviços/curiosidades, acessada em Maio 2003.

12. Bernal, M. P.; Navarro, A. F.; Sanchez-Monedero, M. A.; Roig, A.; Cegarra, J.; Soil Biol. Biochem. 1998, 30, 305.

13. Bernal, M. P.; Paredes, C.; Sanchez-Monedero, M. A.; Cegarra, J.; Bioresour. Technol. 1998, 63, 91.

14. Provenzano, M. R.; De Oliveira, S. C.; Silva, M. R. S.; Senesi, N.; J. Agric. Food Chem. 2001, 49, 5874.

15. Saliba, E. O. S.; Rodriguez, N. M.; Morais, S. A. L.; Piló-Veloso, D.; Ciência Rural 2001, 31, 917.

16. Filley, T. R.; Cody, G. D.; Goodell, B.; Jellison, J.; Noser, C.; Ostrofsky, A.; Org. Geochem. 2002, 33, 111.

17. Mangrich, A. S.; Lobo, M. A.; Tanck, C. B.; Wypych, F.; Toledo, E. B. S.; Guimarães, E.; J. Braz. Chem. Soc. 2001, 11, 164.

18. Schinitzer, M.; Barr, M.; Hartenstein, R.; Soil Biol. Biochem. 1984, 16, 371.

19. Rashid, M. A.; Geochemistry of marine humic compounds, Springer Verlag: New York, 1985.

20. Deiana, S.; Gessa, C; Manunza, B.; Rausa, R.; Seeber, R.; Soil Sci. 1990, $150,419$.

21. Foken, U.; Liebezeit, G.; Mar. Geol. 2000, 164, 173. 